\title{
A Community Based Participatory Approach to Training Young Adults to Design and Implement a Social Marketing Framed Lifestyle Intervention on Their College Campus
}

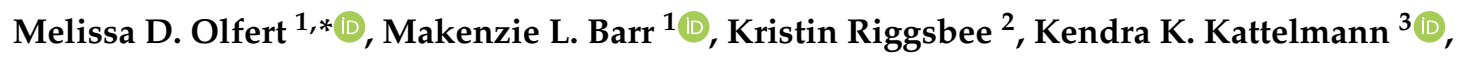 \\ Krista Leischner $^{3}$, Anne E. Mathews ${ }^{4}$ (D), Melissa Vilaro ${ }^{4}$ (D) and Sarah E. Colby ${ }^{2}$ \\ 1 Department of Animal Nutritional Sciences, Davis College of Agriculture, Natural Resources, and Design, \\ West Virginia University, Morgantown, WV 26506, USA; mbarr6@mix.wvu.edu \\ 2 Department of Nutrition, University of Tennessee, Knoxville, TN 37996, USA; kolmstea@vols.utk.edu (K.R.); \\ scolby1@utk.edu (S.E.C.) \\ 3 Health and Nutritional Sciences Department, South Dakota State University, Brookings, SD 57007, USA; \\ kendra.kattelmann@sdstate.edu (K.K.K.); krista.leischner@jacks.sdstate.edu (K.L.) \\ 4 Department of Food Science and Human Nutrition, University of Florida, Gainesville, FL 32611, USA; \\ anne.mathews@ufl.edu (A.E.M.); mgraveley@ufl.edu (M.V.) \\ * Correspondence: Melissa.olfert@mail.wvu.edu; Tel.: +1-304-293-1918
}

Received: 31 July 2018; Accepted: 17 September 2018; Published: 19 September 2018

\begin{abstract}
Background: Using a Community-Based Participatory Research (CBPR) approach may increase the likelihood of relevance and acceptability of the designed intervention, especially on a college campus. Furthermore, recruiting and training college students to design a social marketing framed healthy lifestyle intervention for their peers will allow the intervention to be tailored to the needs of the campus. Objectives: To describe the process of online-course training college students to develop a campus-based, social marketing health promotion intervention. Methods: Four universities recruited current college students (18+ y.o.) to develop a social marketing and environmental intervention (SMEI), which was completed during a 16-week, online/in-person hybrid semester course. Researchers and Extension professionals trained students to design 24 weeks of intervention events that would be implemented the upcoming year. Results: Seventy-eight students enrolled in the study and social marketing and environmental intervention course among the four intervention states (Florida $=30$, South Dakota $=8$, Tennessee $=13$, West Virginia $=27$ ); students were predominately Caucasian $(65.8 \%)$, females $(84.0 \%)$, and sophomore status in college $(64.9 \%)$. Throughout the semester, students assessed their campus environments, set priorities, and developed weekly events and resources needed to implement the intervention on their campuses. By the end of the semester, with researcher support, students had designed 24 weeks of intervention events (marketing, recruiting, and implementation) focusing on nutrition/food/diet, physical activity, stress management, sleep, and time management. These events and resources were catalogued into a digital toolkit of instructions and activities for each week of intervention events. Conclusion: Using a Community-Based Participatory Research approach with college students interested in health allows for the development of an intervention that stems from grass roots efforts and is tailored to the acceptability and needs of their peers.
\end{abstract}

Keywords: community engaged research; college health; training 


\section{Background}

Obesity is a continuing public health concern, spanning all segments of the population. The Centers for Disease Control (CDC) estimates that one in three adults in the United States is considered to be overweight or obese [1]. Furthermore, obesity statistics for the adolescent population, specifically college-aged individuals, are just as dire [1,2]. The rising adolescent obesity rate is concerning because of the risk associated with adult obesity, with some studies establishing obesity in adolescence as a predictor of overweight and obesity in adulthood [1].

Although genetics contribute to obesity, it is unlikely that biology alone is the cause of its increased prevalence; thus, researchers have begun focusing on behavioral and environmental aspects to target obesity prevention, specifically in college-aged individuals [3]. However, findings from these studies have shown mixed results and often lack longitudinal effects of long-term health outcomes [4,5]. One potential downfall of research targeted at college-aged individuals is that this population is often unaccepting of obesity prevention programs and events.

One avenue to improve acceptability of obesity prevention programs by a college-aged population can be addressed through use of Community Based Participatory Research (CBPR) methods [5-8]. The approach of CBPR values both community members and academics as equal collaborators and experts in the research process [9]. This process allows individuals who would previously be participants in studies to contribute to the content development, implementation, evaluation, and sustainability of the intervention. To examine CBPR framework and theory, it has been explained by four main dimensions including context, group dynamics, interventions, and outcomes have been proposed and mapped by Belone et al. in 2014, and are briefly described [10]. Among definitions put forth by authors, the 'context' dimension includes factors that influence researcher/community partnerships include social determinants, environments, policies, historical context of trust/mistrust, university and community capacities to engage in participatory research, and importance of the health issue to the community [10]. The group dynamic dimension includes structural, individual and relational factors [10]. Likewise, if these partnerships are dynamic, this can impact the intervention dimension. Within this intervention dimension, factors include the amount of influence community partners have on the methods and instruments used in the intervention design and the extent of how research findings are translated. Lastly, within the outcomes dimension are factors that improve health and social justice through policy changes, power changes, sustainability, and cultural renewal [10]. Ultimately, this allows for the development of an intervention that is more relatable and relevant to the target population. Specifically, when targeting youth, or college students, peer input is critical to the success of the project that an engaging social marketing campaign and enjoyable intervention materials are created.

Likewise, social marketing approaches, dating back to the 1970s, have been an avenue to target community behavior changes through the development of activities to benefit a target population [11-13]. Current strategies take historical methods of social marketing through analyzing the environment, selecting your target population, designing your strategies, planning programs, and implementing, while also incorporating advancements in technology to enhance their programs [11-13]. Among the public health sector, social marketing strategies have been used in arenas including teen pregnancy [14,15], texting while driving [16], smoking cessation [17,18], and violence $[19,20]$, to name a few [21]. To fully understand an issue facing a certain population and targeting it with social marketing, gaining knowledge from the target population itself is vital. The information taken from these groups can be captured, improved upon, and reliable in advising interventions when using CBPR.

Although CBPR has previously been used in the college-aged population, minimal literature exists concerning a cohort of college student partners informing, developing and implementing an intervention [9]. Various studies include student partners taking part in only one or two vital intervention developing avenues such as, simply informing the intervention's background only through information gathering focus groups or surveys, designing data collection tools such 
as questionnaires, collecting data only, analyzing data only, presenting research findings only, or a minimal combination of the former [22-26]. Consequently, there is room for improvement when involving college students entirely in the informing, designing, implementing, and data collection of a college-based intervention on their campuses. The present study attempts to fill this void and contribute novelty to the sustainability of future obesity prevention programs by reporting strategies to identify and train a group of college-aged CBPR interventionists to design and implement a peer-led intervention. To our knowledge this project brings to light, new approaches to implementing a lifestyle intervention for a target population by using a cohort of the population to inform and drive the content. Therefore, the purpose of this article is to describe the process of training college students to develop a campus-based, social marketing health promotion intervention. Specifically, (1) describe Get Fruveds' CBPR approach to training college students to design a digitally accessible social marketing framed health promotion intervention and toolkit and (2) present baseline characteristics of the Social Marketing and Environmental Intervention students (further identified as SMEI students) who designed the intervention.

\section{Methods}

The overarching study that students were recruited to partner in, 'Get Fruved' (short for FRUits and VEgtables), is a multi-state, peer-led, social marketing and environmental change obesity prevention campaign funded by the United States Department of Agriculture. Get Fruved uses CBPR to increase healthy lifestyles among a college population, specifically, first year students at higher risk for weight gain and other unhealthy lifestyle behaviors. This portion of the Fruved intervention was the developmental phase and no evaluation of a program took place. Intervention sites included University of Florida (FL), South Dakota State University (SD), University of Tennessee (UT), and West Virginia University (WV).

The multi-state umbrella Institutional Review Board (IRB) at University of Tennessee, Knoxville, approved the study for UT, WVU, and SDSU (IRB approval \#14-09366 B-XP). The University of Florida IRB approved the same strategies for activities at the University of Florida (IRB approval \#2014-U-0547FRUVED). This study was prospectively registered in October 2016 on clinicaltrials.gov, NCT02941497.

\subsection{Recruitment of Participants}

Students interested in healthy living at each of the four intervention university campuses were recruited to become partners in development of the Get Fruved intervention as well as be a participant and have data collected on them. Recruitment (during fall semester 2014) for a three-credit hybrid online/in-person course (to be held spring semester 2015) was performed through campus-wide announcements, social media, flyers, word of mouth, informational meetings, and campus informational booths. In addition, recruiters emailed student organizations, spoke to first and second-year level courses, designed short recruitment videos, and reached out to the universities' health organizations. Upperclassmen students (primarily sophomore and junior status) were preferentially recruited because they were familiar with the territory, were on campus the upcoming year to help implement the intervention, and understood the need for a lifestyle intervention at their university. Recruitment took place between August and December 2015 with a total retention of 78 students enrolled in the study and SMEI course among the four intervention states (FL $=30$, $\mathrm{SD}=8, \mathrm{TN}=13, \mathrm{WV}=27$ ). Students were informed that hourly pay would be possible if they were to implement the intervention the upcoming year. Details of recruitment methods are discussed in Table 1 and previously described [27]. Students also completed physical assessments (data not shown) and a behavioral questionnaire including demographics, year in school, and grade point average (GPA). 
Table 1. Student recorded recruitment strategies.

\begin{tabular}{ccc}
\hline Recruitment Method & $\mathbf{N}$ & $\mathbf{\%}$ \\
\hline Class Announcements & 36 & 27.9 \\
Other Organizations & 20 & 15.5 \\
Friend & 19 & 14.7 \\
Professor & 17 & 13.2 \\
Advertising on campus & 17 & 13.2 \\
Email & 10 & 7.7 \\
Other & 10 & 7.7 \\
Total & 129 & 100 \\
\hline
\end{tabular}

\subsection{Training}

The semester training of these student partners was facilitated through a special topics course taught simultaneously at each university. This course was a hybrid structure conducted partially online and partially in person over the duration of a university semester (15-week). The online portion of the class was conducted via Zoom, a video conference platform, as well as Wikispaces, an online platform that securely houses education materials and files. Students met in a classroom at their respective universities, twice a week, for $1-2 \mathrm{~h}$, and virtually attended lectures and interacted with other students via Zoom video conference. A researcher, Extension professional, or professional from various fields taught each lecture based on their respective area expertise. In CBPR fashion, both student partners and researchers were co-learners in understanding the health related content from an expertise side as well as learning the promotion or barriers to maintaining health on each college campus. The lecture would provide SMEI students with information to develop a comprehensive lifestyle intervention. Weekly topics for the course are outlined in Table 2.

Table 2. Semester course topics.

\begin{tabular}{ccc}
\hline Week & Tuesday & Thursday \\
\hline & Course Overview & Pre-Assessments \\
1 & Behavior Change & Social Marketing \\
2 & Healthy Body Image & Promoting Health \\
3 & Communication Strategies & Environmental Assessment \\
4 & Built Environment Assessments & Built Environment Assessments \\
5 & Built Environment Assessments & Built Environment Assessments \\
6 & Built Environment Discussions & Cultural Diversity \\
7 & Individual Topic Area Work & Individual Topic Area Work \\
8 & Individual Topic Area Work & Individual Topic Area Work \\
9 & Individual Topic Area Work & Individual Topic Area Work \\
10 & Individual Topic Area Work & Individual Topic Area Work \\
11 & Individual Topic Area Work & Individual Topic Area Work \\
12 & Individual Topic Area Work & Individual Topic Area Work \\
13 & Leadership, Policy \& Advocacy & No Class \\
14 & \multicolumn{2}{c}{ Presentations at Fruved Summit } \\
15 & \multicolumn{2}{c}{ Post Assessments } \\
16 & \multicolumn{2}{c}{}
\end{tabular}

Following lectures, students were given discussion questions that challenged them to apply the knowledge gained during lecture to their campus environments and ultimately intervention event design. Discussion questions regarding the content and how to implement this knowledge of their campuses were recorded and transcribed by researchers and uploaded onto the Wikispaces online platform. Themes from these discussions were used by the students as the basis for development of the intervention events. As an example, when discussing health promotion, although students felt there were programs on campus for that, they identified that dining and convenience stores on campus did not promote or label healthier options. 
A unique aspect of the course was collaborating with collegiate 4- $\mathrm{H}$ (college and universities 4-H student organization) and Extension experts. Students on three of the four universities became collegiate 4- $\mathrm{H}$ members and a portion of enrolled students also received the opportunity to attend a 4-H camp on "Essential Elements of 4-H Youth Development Programs." Throughout the two-day training camp, students progressed through activities and discussions on how to properly communicate and serve as a role model, provide a safe and inclusive environment, and allow their future participants to master the intervention's health-related content. These elements were taken into considerations and used when designing their intervention events.

\subsection{Environmental Audit}

Evaluating the surrounding campus environment is another key to success when implementing a healthy lifestyle intervention [28-31]. Understanding the current layout of an areas and the resources available is vital to designing feasible events. Therefore, in the present study students from each respective university also conducted environmental audits of their own campus to evaluate the healthfulness of their site and resources.

Students were divided into equal teams and given a specific section of the Healthy Campus Environmental Audit (HCEA), developed by researchers within the Healthy Campus Research Consortium (HCRC) multi-state group. These tools identify, within the campus environment, facilitators or barriers to leading a healthy lifestyle [32]. Factors assessed within the HCEA included: (1) recreational facilities; (2) vending machines; (3) convenience stores; (4) dining options; (5) walkability/bikeability, and (6) policy. Students were trained per HCEA protocols to assess and provide quantitative information on one aspect of their campus environment. All HCEA evaluations were captured through online portals so that data represented all intervention schools (data not shown).

Students were able to identify areas with potential for bringing student engaged changes and further making healthful adjustments in their campus environment using the HCEA tools [28-31,33-35]. These audits expanded understanding of the campus environment alone with barriers and successes. Using these audits allowed students to understand and acknowledge aspects of their campus when developing the Fruved intervention.

\subsection{Intervention Development}

Upon completing course training and HCEA, students were tasked with development of the Get Fruved intervention. Feasible intervention events were developed based on findings from the HCEA and educational training. Due to the large scale of the intervention, students were divided into 24 teams and assigned a topic area based around the three core themes of physical activity, diet, and stress management. Teams were then given the task of developing a comprehensive week of events based around their topic focus and allowed six weeks to develop all portions of their event. Researchers worked weekly with each team to assist in development of events and materials to ensure feasibility of the events and ideas on each campus. At each weekly meeting, team members presented their current work to the researcher to allow for open dialogue and conversation to improve materials.

After event ideas were planned, teams designed marketing and educational materials for their topic area. Students were required to design one large Friday event with a grand prize giveaway, corresponding social media posts, a tabling event to promote their Friday event, flyers for advertisement, flyers for education, a stepwise toolkit of their event information, and a budget for the week. The promotional materials were designed on electronic platforms and available for distribution through various social media platforms. Teams also developed a final PowerPoint presentation of their materials that would be presented to their peers at the 'Fruved Summit' at the University of Tennessee, Knoxville. 


\subsection{Toolkit Development}

Students from the four Fruved intervention universities met in Knoxville, TN for a "Fruved Summit" to present their event ideas. Students met with their respective teams from each state to collaborate and brainstorm for the upcoming year. During this summit, all researchers and students reviewed the proposed events and determined the most feasible for implementing at all universities. Once a conclusion was drawn by all partners (student and researcher), events were finalized.

After the Fruved summit, researchers compiled the students' events into a comprehensive digital platform or, 'Fruved Intervention Toolkit,' which was a digital document of the plan of events for the upcoming year. Events were ordered for cohesion, typical weather, and in alignment with other national initiatives (e.g., March is National Nutrition Month). After researchers laid a timeline and framework for the toolkit, per CBPR protocol, the SMEI students reviewed and finalized the toolkit. Students were sent the final toolkit to make edits upon as well as attended one video conference call with researchers to make final edits. The entirety of this digital toolkit was available for researcher and student-wide use on a password protected online platform. Due to the spread of universities and students across the United States, a platform was needed to ensure all parties were able to access the content and download resources (flyers, evidence-based information, figures, photos, etc.). The final toolkit was available on the Wikispaces platform.

\section{Results}

\subsection{Characteristics}

Characteristics from baseline demographic data collection are identified in Table 3. Seventy-eight SMEI students (enrolled as both CBPR partners and study participants) registered in the semester course training were predominately self-reported to be Caucasian $(65.8 \%)$, females $(84.0 \%)$, at sophomore status in college $(64.9 \%)$, with a GPA of (Table 3). Average age of the SMEI group was 20 years old.

Table 3. Demographics Characteristics of SMEI Students.

\begin{tabular}{ccc}
\hline Variable & $\mathbf{N}$ & $\mathbf{\%}$ \\
\hline Sex & & \\
Male & 12 & 16.0 \\
Female & 63 & 84.0 \\
Age & & \\
18 & 6 & 8.0 \\
19 & 26 & 35.1 \\
20 & 29 & 39.2 \\
21 & 9 & 12.2 \\
22 & 0 & 0 \\
23 & 1 & 1.4 \\
24 & 1 & 1.4 \\
More than 24 & 2 & 2.7 \\
Ethnicity & & \\
White only & 48 & 65.8 \\
Black only & 3 & 4.1 \\
Hispanic/Latino only & 2 & 2.7 \\
Other (including bi-racial) & 20 & 29.4 \\
Year & & \\
Freshman & 8 & 10.8 \\
Sophomore & 48 & 64.9 \\
Junior & 13 & 17.6 \\
Senior & 4 & 5.4 \\
Graduate & 1 & 1.4 \\
\hline
\end{tabular}


Table 3. Cont.

\begin{tabular}{ccc}
\hline Variable & $\mathbf{N}$ & $\mathbf{\%}$ \\
\hline GPA & & \\
$3.5-4.0$ & 25 & 33.8 \\
$3.0-3.49$ & 35 & 47.3 \\
$2.5-2.9$ & 9 & 12.2 \\
$2.0-2.49$ & 1 & 1.4 \\
Under 2.0 & 0 & 0 \\
\hline
\end{tabular}

\subsection{Fruved Toolkit}

Upon completion of the 15-week course, students developed 24-week of intervention events to be implemented on their campuses the upcoming year. Table 4 lists the layout and topic names of each week as well as the lead university on each week. A Fruved Toolkit was developed into a paper version and electronic version for students to use during the implementation year. This toolkit was used to run events and be refined by SMEI student partners as problems arose throughout the project.

Table 4. Toolkit Topic Weeks and Leads.

\begin{tabular}{cccc}
\hline Week & Topic & Type of Topic & Lead \\
\hline 1 & Get Fruved & All Teams & WV \\
2 & My Plate & Diet & WV \\
3 & Yoga & Physical Activity & UF \\
4 & Cardio & Physical Activity & UF \\
5 & Music & Stress & WV \\
6 & Time Management & Stress & SD \\
7 & Dance & Physical Activity & UT \\
8 & Meditation & Stress & UT \\
9 & Fiber & Diet & WV \\
10 & Flexibility & Physical Activity & UT \\
11 & Perfect Portions & Diet & SD \\
12 & Thanksgiving & All Teams & SD \\
13 & Get Fruved & All Teams & UT \\
14 & Strength & Physical Activity & SD \\
15 & Positivity & Stress & SD \\
16 & Sleep Week & Stress & WV \\
17 & Friendships & Stress & WV \\
18 & Substance Abuse & Stress & SD \\
19 & Body Image & Stress & UT \\
20 & Try Something New & Diet & UT \\
21 & Hydration & Diet & UF \\
22 & Savor Flavor & Diet & UF \\
23 & Steps & Physical Activity & UF \\
24 & Maintaining Healthy & All Teams & UF \\
& Lifestyles & & \\
\hline
\end{tabular}

Intervention events were formulated into a cohesive toolkit to be laid out equally between university leads. This allowed for each university to provide comprehensive steps (marketing with social media and print advertising, mid-week promotional event, and large main event) to the other universities. An example of a weekly event is detailed in Table 5. These events placed into a toolkit were provided to each university to run their intervention upon the next consecutive year. Each university was lead of six weeks throughout the 2015-2016 year and each of the five teams on each campus was lead of one week (total of 24 weeks of intervention events were completed at each campus). All universities participated in each weekly event on their respective campuses. 
Table 5. Healthy Body Image Event Example.

\begin{tabular}{|c|c|}
\hline \multicolumn{2}{|r|}{ Online Interactive Event: Compliment YOU! } \\
\hline Objective & $\begin{array}{c}\text { By the end of the week, } 30 \text { students will post and tag Fruved on social media with } \\
\text { a personal compliment. }\end{array}$ \\
\hline Activity & Share a non-appearance-based compliment about yourself! \\
\hline Tips & $\begin{array}{l}\text { Start with promotion of the activity and have a few example posts from your } \\
\text { organization members; get the ball rolling! }\end{array}$ \\
\hline \multicolumn{2}{|r|}{ Small Event: Compliment Table } \\
\hline Event Objective & By the end of the event, 30 students will submit compliments about themselves. \\
\hline Activity & $\begin{array}{c}\text { Set up a compliment table on campus } \\
\text { Students enter the weekly giveaway by submitting a non-appearance-based } \\
\text { compliment about themselves, placed into a bowl } \\
\text { Pull one winner announced on social media } \\
\text { Optional: Mirrorless Monday } \\
\text { Partner with another organization (residence hall association) to cover mirrors } \\
\text { and write positive messages/affirmations in their place }\end{array}$ \\
\hline Resources & $\begin{array}{c}\text { 2-3 h of time } \\
1 \text { Table } \\
\text { 2-3 Fruved student workers } \\
\text { Paper and pens for compliments } \\
\text { Box or bowl } \\
\text { Educational materials: healthy body image facts }\end{array}$ \\
\hline Giveaways & Spa/massage gift card \\
\hline
\end{tabular}

\section{Discussions}

Among four intervention sites, 78 enrolled in the study and SMEI course students and were predominately Caucasian, sophomore females. By the end of an academic semester, the students had designed 24 weeks of intervention events focusing on nutrition/food/diet, physical activity, stress management, sleep, and time management. SMEI students designed interactive events, advertisements, artwork, and social media posts for the intervention. These events and resources were catalogued into a digital toolkit of instructions and activities for each week of intervention events. Training students to be social marketing and environmental interventionists via the CBPR process allowed for the development of an intervention.

There is little reported in the current literature regarding the effectiveness and feasibility of recruiting young adults, and specifically college students, to participate in CBPR. Perhaps the greatest benefit of involving students and having them design and implement an intervention for their peers is the likelihood that the intervention will be well-received. Previous work using a CBPR framework has captured the ability to develop appropriate research, recruit adequate participants and partners, maintain working relationships to maintain quality outputs, and ensure sustainability of programs as a result of community participant buy-in [36]. Briefly, within the realm of this intervention and the use of CBPR framework, student partners were charged with understanding their campus and what influences their health and well-being (context dimension), engage in knowledge sharing about their experiences and campus with researchers and peers (group dynamics dimension), use their knowledge and learning to design intervention events (intervention dimension), and be a driver in the intervention implementation and influence change (outcomes dimension). When taking these aspects into consideration with the current project, the framework of CBPR is used to drive this training and intervention design [10].

From the current work, the use of college students in the development of a lifestyle intervention on a college campus aided in the development of 24 -weeks of health intervention events from authentic students on each campus $[4,6,9,37-43]$. The students described here were immersed in a research 
intervention on their campuses that sought to create a positive impact in the environment by generating action from peer leaders to their peers. This unique experience afforded the students significant responsibility and a personal investment in the research and development of the intervention. Our approach being used in a higher education curriculum for individuals interested in lifestyle interventions can enhance the hands-on learning for future researchers during their college career. This can additionally assist current researchers by using a variety of thoughts and ideas to enrich the quality of programs. Furthermore, this approach could be disseminated into current higher education curriculum or extracurricular programs through feedback and data of student suggestions for learning.

Various experts and fields of study came together for the virtual training of these students. The online portion of the class, conducted via Zoom, and the online platform that securely housed education materials and files, Wikispaces, ensured all student participants were participating from a digital platform. The end result of the training was a compilation of necessary, comprehensive, introductory information for a research-based, social marketing framed healthy lifestyle intervention, including promotional marketing ranging from web-based flyers to timed social media posts. Through a semester of training, these students created a 24-week toolkit to implement on each campus the following year. Designing the intervention and a digital toolkit allowed for as wide-spread accessibility as well as sustainability and dissemination of the project in the future. This intervention provides a novel approach to CBPR by specifically training college students from four unique locations to design and implement a social marketing framed healthy lifestyle intervention on their own campus.

Some challenges and limitations with the training of college students to design an intervention is finding individuals' who are motivated and want to learn and deliver a quality intervention. Due to this, some sample sizes of SMEI students were smaller at some universities causing those minimal students to undertake a large development of intervention information. However, this was to be alleviated by enrolling students for university credit, through help from researchers, and by allowing them to receive monetary incentive the upcoming year for implementing their intervention content. Furthermore, some intervention events were not feasible at each university and needed to be fine-tuned on certain campuses due to weather, terrain, and resource differences. Additional limitations of the current study are the lack of qualitative or quantitative evaluation data on the experiences each SMEI, CBPR partner had while taking the course. As this initial study objective was to explain the training aspect of college students in development of health intervention, the lack of evaluation and determinants of success is a barrier. However, this study will provide preliminary support to show the protocol and development of a peer-led lifestyle intervention when using upperclassmen college students as partners in development.

Although CBPR has previously been used in the college-aged population, there is little research examining the cohort of those developing and implementing the intervention [9]. The present study seeks to contribute to the sustainability of future obesity prevention programs by reporting strategies in training a group of college students to develop a campus-based, social marketing framed health promotion intervention through CBPR approaches.

Within the population of upperclassmen students at four universities in the United States, a training course provided students with the education and resources to design a social marketing framed healthy lifestyle intervention. Students were educated in areas of wellness, social media, and marketing and designed a 24-week intervention toolkit that provided each university the necessary materials to implement a healthy lifestyle intervention on their campuses the following year. While also training these students on background information for healthy living, researchers were able to also gain insight into maintaining health on campus through the student's experiences and environmental audits. Training students to be social marketing and environmental interventionists via the CBPR process allows for the development of an intervention that stems from grass roots efforts and is tailored to the acceptability and needs of their peers. This study describes the training of students and their collaborative effort in designing and development of a peer-led social marketing campaign to improve healthier lifestyles among incoming college students. 
Author Contributions: Research design was developed by the multidisciplinary team of S.E.C., M.D.O., A.E.M., and K.K.K. The intervention was performed by S.E.C., M.D.O., A.E.M., and K.K.K., M.L.B., K.R., and K.L. Data analysis was done by M.D.O. and M.L.B. and statistical analysis was carried out by M.D.O. and M.L.B. Writing of the manuscript was done by M.L.B., M.D.O. and S.E.C. and final content was reviewed by M.D.O. Additional review of interpretation and manuscript editing was provided by A.E.M., K.K.K., K.R., K.L. and M.V. All authors have read and approved the final manuscript.

Funding: This project was supported by Agriculture and Food Research Initiative Grant no. 2014-67001-21851 from the USDA National Institute of Food and Agriculture, "Get Fruved": A peer-led, train-the-trainer social marketing intervention to increase fruit and vegetable intake and prevent childhood obesity-A2101.

Acknowledgments: We would like to thank the engagement and involvement of the research participants. Further we would like to lank our multistate partners from the Healthy Campus Research Consortium.

Conflicts of Interest: The authors declare no conflict of interest.

Ethical statement: Ethics approval and consent to participate: The multi-state umbrella Institutional Review Board at University of Tennessee, Knoxville, approved all recruitment strategies of the study for University of Tennessee, West Virginia University, and South Dakota State University (IRB approval \#14-09366 B-XP). The University of Florida IRB approved the same strategies for activities at the University of Florida (IRB approval \#2014-U-0547FRUVED).

Declarations: The datasets generated and/or analyzed during the current study are not publicly available due the ability of individuals to be identified, and the study is currently ongoing, but are available from the corresponding author on reasonable request.

\section{References}

1. Ogden, C.L.; Carroll, M.D.; Kit, B.K.; Flegal, K.M. Prevalence of childhood and adult obesity in the United States, 2011-2012. JAMA 2014, 311, 806-814. [CrossRef] [PubMed]

2. Skinner, A.C.; Skelton, J.A. Prevalence and trends in obesity and severe obesity among children in the United States, 1999-2012. JAMA Pediatr. 2014, 168, 561-566. [CrossRef] [PubMed]

3. Sleddens, E.F.; Kroeze, W.; Kohl, L.F.; Bolten, L.M.; Velema, E.; Kaspers, P.J.; Brug, J.; Kremers, S.P. Determinants of dietary behavior among youth: An umbrella review. Int. J. Behav. Nutr. Phys. Act 2015, 12, 7. [CrossRef]

4. Bogart, L.M.; Elliott, M.N.; Uyeda, K.; Hawes-Dawson, J.; Klein, D.J.; Schuster, M.A. Preliminary healthy eating outcomes of SNaX, a pilot community-based intervention for adolescents. J. Adolesc. Health 2011, 48, 196-202. [CrossRef] [PubMed]

5. Salimi, Y.; Shahandeh, K.; Malekafzali, H.; Loori, N.; Kheiltash, A.; Jamshidi, E.; Frouzan, A.S.; Majdzadeh, R. Is community-based participatory research (CBPR) useful? A systematic review on papers in a decade. Int. J. Prev. Med. 2012, 3, 386-393.

6. Gibson, J.E.; Flaspohler, P.D.; Watts, V. Engaging youth in bullying prevention through community-based participatory research. Fam. Community Health 2015, 38, 120-130. [CrossRef]

7. Minkler, M.; Wallerstein, N. Community-Based Participatory Research for Health: From Process to Outcomes; John Wiley \& Sons: San Francisco, CA, USA, 2011.

8. Wallerstein, N.; Duran, B. The conceptual, historical, and practice roots of community-based participatory research and related participatory traditions. CBPR 2003, 27-52.

9. Jacquez, F.; Vaughn, L.M.; Wagner, E. Youth as partners, participants or passive recipients: A review of children and adolescents in community-based participatory research (CBPR). Am. J. Community Psychol. 2013, 51, 176-189. [CrossRef] [PubMed]

10. Belone, L.; Lucero, J.E.; Duran, B.; Tafoya, G.; Baker, E.A.; Chan, D.; Chang, C.; Greene-Moton, E.; Kelley, M.A.; Wallerstein, N. Community-based participatory research conceptual model:community partner consultation and face validity. Qual. Health Res. 2016, 26, 117-135. [CrossRef] [PubMed]

11. Kotler, P.; Roberto, E.L. Social Marketing: Strategies for Changing Public Behavior; Free Press: New York, NY, USA, 1989.

12. Kotler, P.; Zaltman, G. Social marketing: An approach to planned social change. J. Mark. 1971, 35, 3-12. [CrossRef] [PubMed]

13. Andreasen, A.R. Social marketing: Its definition and domain. J. Public Policy Mark. 1994, 13, 108-114.

14. Willoughby, J.F. Effectiveness of a social marketing campaign promoting use of a sexual health text service by teens. J. Health Commun. 2015, 20, 1206-1213. [CrossRef] [PubMed] 
15. Ponsford, R.; Allen, E.; Campbell, R.; Elbourne, D.; Hadley, A.; Lohan, M.; Melendez-Torres, G.J.; Mercer, C.H.; Morris, S.; Young, H.; et al. Study protocol for the optimisation, feasibility testing and pilot cluster randomised trial of positive choices: A school-based social marketing intervention to promote sexual health, prevent unintended teenage pregnancies and address health inequalities in England. Pilot Feasibility Stud. 2018, 4, 102. [PubMed]

16. Buccoliero, L.; Bellio, E.; Mazzola, M.; Solinas, E. The role of social marketing communications in influencing "text and driving" behaviors: Theory and evidence from an international sample. GSTF GBR 2018, 4. [CrossRef]

17. Maksimovic, L.; Shen, D.; Bandick, M.; Ettridge, K.; Eckert, M. Evaluation of the pilot phase of the 'Give up smokes for good' social marketing campaign. Health Promot. J. Aust. 2015, 26, 16-23. [CrossRef] [PubMed]

18. Campbell, M.A.; Finlay, S.; Lucas, K.; Neal, N.; Williams, R. Kick the habit: A social marketing campaign by Aboriginal communities in NSW. Aust. J. Primary Health 2014, 20, 327-333. [CrossRef] [PubMed]

19. Hull, S.J.; Davis, C.R.; Hollander, G.; Gasiorowicz, M.; Jeffries, W.L.; Gray, S.; Bertolli, J.; Mohr, A. Evaluation of the acceptance journeys social marketing campaign to reduce homophobia. Am. J. Public Health 2016, 107, 173-179. [CrossRef] [PubMed]

20. Spears, B.; Taddeo, C.; Barnes, A.; Scrimgeour, M.; Collin, P.; Drennan, J.; Razzell, M. Keep It Tame: Promoting Respect Online Safe and Well Online Pilot Study: Evaluating the Design, Engagement and Impact of a Social Marketing Approach Aimed at 12 to 18 Year Olds. Available online: https://eprints.qut.edu.au/86108/ (accessed on 19 September 2018).

21. Craig Lefebvre, R.; Flora, J.A. Social marketing and public health intervention. Health Educ. Q. 1988, 15, 299-315. [CrossRef]

22. Heckel, E.; Moore, C.D. Community-based participatory research: The college as the focal community. JBSW 2009, 14, 45-61.

23. Bulmer, S.M.; Barton, B.A.; Liefeld, J.; Montauti, S.; Santos, S.; Richard, M.; Hnath, L.; Pelletier, K.; Lalanne, J. Using CBPR methods in college health research: Exploring excessive alcohol consumption. J. Adolesc. Res. 2015, 31, 232-258. [CrossRef]

24. Reinschmidt, K.M.; Maez, P.; Iuliano, J.E.; Nigon, B.M. Using active learning strategies linked to CBPR principles in a semester-long class project to teach qualitative research methods in public health. Pedag. Health Promot. 2018. [CrossRef]

25. Lopez, E.D.; Sharma, D.K.; Mekiana, D.; Ctibor, A. Forging a new legacy of trust in research with Alaska Native college students using CBPR. Int. J. Circumpolar Health 2012, 71, 18475. [CrossRef] [PubMed]

26. Boyd, J.K.; Hernandez, J.Y.; Braun, K.L. Engaging nurse aide students to develop a survey to improve enrollment and retention in college. PCHP 2011, 5, 169-176. [CrossRef] [PubMed]

27. Barr, M.L.; Olfert, M.D.; Zhou, W.J.; Riggsbee, K.; Mathews, A.E.W.; Vilaro, M.; Kattelmann, K.K.; Andrea, H.; White, A.; Horacek, T.; et al. Recruitment strategies implemented across a four-state lifestyle intervention: Get fruved study. FASEB 2016, 30, 674.37.

28. Byrd-Bredbenner, C.; Johnson, M.; Quick, V.M.; Walsh, J.; Greene, G.W.; Hoerr, S.; Colby, S.M.; Kattelmann, K.K.; Phillips, B.W.; Kidd, T.; et al. Sweet and salty. An assessment of the snacks and beverages sold in vending machines on US post-secondary institution campuses. Appetite 2012, 58, 1143-1151. [PubMed]

29. Horacek, T.M.; Erdman, M.B.; Byrd-Bredbenner, C.; Carey, G.; Colby, S.M.; Greene, G.W.; Guo, W.; Kattelmann, K.K.; Olfert, M.; Walsh, J.; et al. Assessment of the dining environment on and near the campuses of fifteen post-secondary institutions. Public Health Nutr. 2013, 16, 1186-1196. [CrossRef] [PubMed]

30. Horacek, T.M.; Erdman, M.B.; Reznar, M.M.; Olfert, M.; Brown-Esters, O.N.; Kattelmann, K.K.; Kidd, T.; Koenings, M.; Phillips, B.; Quick, V.; et al. Evaluation of the food store environment on and near the campus of 15 postsecondary institutions. Am. J. Health Promot. 2013, 27, e81-e90. [CrossRef] [PubMed]

31. Horacek, T.M.; White, A.A.; Greene, G.W.; Reznar, M.M.; Quick, V.M.; Morrell, J.S.; Colby, S.M.; Kattelmann, K.K.; Herrick, M.S.; Shelnutt, K.P.; et al. Sneakers and spokes: An assessment of the walkability and bikeability of US postsecondary institutions. J. Environ. Health 2012, 74, 8. [PubMed]

32. Kattelmann, K.K.; White, A.A.; Greene, G.W.; Byrd-Bredbenner, C.; Hoerr, S.L.; Horacek, T.M.; Kidd, T.; Colby, S.; Phillips, B.W.; Koenings, M.M.; et al. Development of young adults eating and active for health (YEAH) internet-based intervention via a community-based participatory research model. J. Nutr. Educ. Behav. 2014, 46, S11-S25. [CrossRef] [PubMed] 
33. Horacek, T.; Szklany, K.; Esters, O.; Shelnutt, K.; Morrell, J.; Kattelmann, K. Development and testing of a healthy campus environmental audit and the lean index. J. Nutr. Educ. Behav. 2011, 43, S22. [CrossRef]

34. Horacek, T.M.; Olfert, M.; Byrd-Bredbenner, C.; Carey, G.; Colby, S.; Greene, G.; Hoerr, S.; Kattelmann, K.K.; Kidd, T.; Keonings, M.; et al. Environmental supports for physical activity and healthy snacking vary across campus. J. Acad. Nutr. Diet. 2012, 112, A62. [CrossRef]

35. Horacek, T.M.; White, A.A.; Byrd-Bredbenner, C.; Reznar, M.M.; Olfert, M.D.; Morrell, J.S.; Koenings, M.M.; Brown, O.N.; Shelnutt, K.P.; Kattelmann, K.K.; et al. PACES: A physical activity campus environmental supports audit on university campuses. Am. J. Health Promot. 2014, 28, e104-e117. [CrossRef] [PubMed]

36. Jagosh, J.; Bush, P.L.; Salsberg, J.; Macaulay, A.C.; Greenhalgh, T.; Wong, G.; Cargo, M.; Green, L.W.; Herbert, C.P.; Pluye, P. A realist evaluation of community-based participatory research: Partnership synergy, trust building and related ripple effects. BMC Public Health 2015, 15, 725. [CrossRef] [PubMed]

37. Christiansen, E.D. Adolescent cape verdean girls' experiences of violence, incarceration, and deportation: Developing resources through participatory community-based groups. IJIR 2010, 34, 127-140. [CrossRef]

38. Diamond, S.; Schensul, J.J.; Snyder, L.B.; Bermudez, A.; D'Alessandro, N.; Morgan, D.S. Building Xperience: A multilevel alcohol and drug prevention intervention. Am. J. Community Psychol. 2009, 43, $292-312$. [CrossRef] [PubMed]

39. Mance, G.A.; Mendelson, T.; Byrd, B., III; Jones, J.; Tandon, D. Using community-based participatory research to adapt a mental health intervention for African American emerging adults. PCHP 2010, 4, 131-140. [PubMed]

40. Meininger, J.C.; Reyes, L.R.; Selwyn, B.J.; Upchurch, S.L.; Brosnan, C.A.; Taylor, W.C.; Villagomez, E.; Quintana, V.; Pullis, B.; Caudill, D.; et al. A structured, interactive method for youth participation in a school district-university partnership to prevent obesity. J. Sch. Health 2010, 80, 493-500. [CrossRef] [PubMed]

41. Mendenhall, T.; Heather, W.; Harper, P.; Haas, S. Students against nicotine and tobacco addiction (SANTA): Community-based participatory research in a high-risk young adult population. Fam. Syst. Health 2008, 26, 225. [CrossRef]

42. Mooney-Somers, J.; Erick, W.; Scott, R.; Akee, A.; Kaldor, J.; Maher, L. Enhancing Aboriginal and Torres Strait Islander young people? s resilience to blood-borne and sexually transmitted infections: Findings from a community-based participatory research project. Health Promot. J. Aust. 2009, 20, 195-201. [CrossRef]

43. Noone, J.; Sullivan, M.; McKinnis, N.C.; Allen, T.L.; Regalado, C.; Esqueda, T. Latino youth participation in community-based participatory research to reduce teen pregnancy disparities. Child. Youth Serv. Rev. 2016, 63, 36-39. [CrossRef] 